\title{
Çocukların Bilişsel İşlevlerinde Hemisferik Asimetriler
}

\author{
Hemispheric Asymmetries in Children's Cognitive Functions
}

\begin{abstract}
Evrim GÜLBETEKIN*
Öz: Sağ ve sol beyin görünümü bakımından benzer olmasına karşın, işlevleri yönünden çeşitli özelleşmeler göstermektedir. Yetişkinlerle yapılan çok sayıdaki çalışma tipik olarak sol hemisferin sözel ve sayısal işlemlerde; sağ hemisferin ise yüz işleme ve görsel-uzamsal becerilerde uzmanlaştığını ortaya koymuştur. Öte yandan gelişmekte olan beyne sahip olan çocuklardaki hemisferik asimetrilerin yetişkinlerden bazı farklılıklar gösterebileceği düşünülmektedir. Bu nedenle sunulan makalede yetişkinlere göre daha az çalışılmış bir grup olan çocuklarda sol hemisferin özelleşme gösterdiği sözel ve sayısal işlemlere ve sağ hemisferin özelleşme gösterdiği yüz işleme ve görsel-uzamsal işlemlere ilişkin literatüre yer verilmiştir. Ayrıca çocuklarda iki hemisfer arasındaki etkileşiminin gelişimine dair çalışmalara değinilmiştir.
\end{abstract}

Anahtar sözcükler: Hemisferik Asimetri, Yüz İşleme, Sözel-Sayısal İşlemler, Görsel-Uzamsal Beceriler

Abstract: Although, the right and the left brain are similar in their appearance; they have different functional specializations. A large number of studies conducted with adults has indicated that typically the left hemisphere is specialized in verbal and numerical processes, while the right hemisphere is specialized in visual-face processing and visuo-spatial abilities. On the other hand, it was thought that hemispheric asymmetries in children who have developing brains may differ from those of adults. Therefore, in this article, the literature concerning typical left hemispheric functions (verbal and numerical processes) and right hemispheric functions (face processing and visuo-spatial abilities) in -a less studied group- children are reported. In addition the development of inter-hemispheric interaction in children is discussed.

Keywords: Hemispheric Asymmetry, Face Processing, Verbal-Numerical Processing, Visuo-Spatial Abilities

\section{Hemisferik Asimetri}

Beyin kabuğu, anatomik olarak sağ ve sol hemisferden oluşur. Hemisferler, görünüm bakımından oldukça simetrik olmasına rağmen, bilgi işleme tarzı ve bilgi işleme eğilimleri bakımından oldukça farklıdırlar (Hellige 2001). Bu farklılık "hemisferik asimetri" kavramının doğmasına neden olmuştur. Beynin sağ ve sol yarıüresi, sözel beceriler, motor işlemler, görsel-uzamsal işlemler, yüz işleme, sayısal işlemler, müzik becerisi, soyut düşünme ve duygular gibi pek çok alanda özelleşme göstermektedir. İlk olarak fark edilen ve ön plana çıkan özelleşmiş işlev dildir. $\mathrm{Bu}$ asimetri, Paul Broca (1861) tarafindan konuşma bozukluğu olan bir kişinin sol frontal lobunda "Broca alanı" olarak bilinen bir bölgede meydana gelen hasarı tespit etmesiyle ortaya konmuştur. Ancak, sağ yarıkürede aynı alanda meydana gelen hasarın bu tür bir konuşma bozukluğuna yol açmadığı görülmüştür (Atkinson et al. 2002). Dolayısıyla dil becerisi sol hemisfere özgü bir işlevdir.

\footnotetext{
*Yrd. Doç. Dr., Akdeniz Üniversitesi, Edebiyat Fakültesi, Psikoloji Bölümü, Antalya. evrimg@akdeniz.edu.tr
} 
Hemisferik özelleşmeler öncelikli olarak yetişkinlerde çalışılmış olmakla birlikte çocuklarda da yapılan çok sayıdaki çalışma (Chiang et al.1997; Ballantyne \& Trauner 2000; Balsamo et al. 2002; Lebel \& Beaulieu 2009; Tsujii et al. 2009; Thomason et al. 2009; Porta, Kraft \& Harper 2010; Aljuhanay et al. 2010; Hahn, Jansen \& Heil 2010; Kikuchi et al. 2011; Lidzba et al. 2011) benzer asimetrilerin varlığını ortaya koymuştur.

Sunulan makalede yetişkinlerde sol hemisfer özelleşmesinin gözlendiği iki işleme (sözel ve sayısal işlemler) ve sağ hemisfer özelleşmesinin gözlendiği diğer iki işleme (yüz işleme ve görsel-uzamsal işlemler) ilişkin olarak çocuklarla yapılan çalışmaları içeren hemisferik asimetri literatürüne yer verilmiştir.

\section{Sözel İşlemler}

Çocuklarda sözel işlemlere ilişkin hemisferik asimetriler, sözel bilgi işlemede bozukluk gösteren çocuklarda ve normal çocuklarda beyin görüntüleme teknikleri, dikotik dinleme ve görsel yarı-alan teknikleri gibi hemisferik özelleşmeleri test etmeye yarayan yöntemlerin kullanılması yoluyla çalışılmaktadır.

\section{Beyinde Dil İşlemeye İlişsin Yapısal ve İşlevsel Asimetriler}

Beyinde dil işlemekte özelleşme gösterdiği düşünülen Wernicke alanı, planum temporale (PT), arcuate fasciculus gibi yapıların dil işleme görevleri sırasında asimetrik aktivasyon gösterip göstermediği incelenmektedir.

Balsamo ve arkadaşları (2002), çocuklara çeşitli isimlerin tanımlarını sesli olarak dinlettikleri ve çocuklardan tanımlanan nesneyi sessizce anlamlandırmalarını istedikleri bir görev sırasında fMRG (fonksiyonel manyetik rezonans görüntüleme) ile beyin aktivitesini görüntülemişlerdir. Asimetri göstergeleri superior ve orta temporal giruslarda, frontal lobta, inferior frontal girusta, orta frontal girusta ve Wernicke alanında güçlü sol yanallaşma olduğunu göstermiştir. Sonuç olarak 8 yaşlarında yetişkinlerde olduğu gibi sol reseptif alanlarda bir lateralizasyonun ortaya çıktığı bulunmuştur.

Yetişkinlerde el kullanımı, dil gibi işlevsel hemisferik asimetrilerle ilişkili bulunan diğer bir beyin yapısı planum temporale'dir (PT). Fetus ve yeni doğan beyinleri ile yapılan postmortem çalışmalar sola dönük PT asimetrisinin gebeliğin son trimesterindan sonra ortaya çıktığını göstermiştir. Preis, Jancke, Schmitz-Hillebrecht ve Steinmetz (1999) 3-14 yaşları arasındaki normal çocuklarda artan yaş ile birlikte PT morfometrisinde bir değişimin olmadığını gözlemişlerdir. Ancak, kızlarda sol yönlü PT asimetrisinin daha güçlü olduğu gözlenmiştir. Bu bulgu kız çocuklarının sözel becerilerdeki üstünlüğünün sol hemisfer özelleşmesi ile ilişkili olduğuna işaret etmektedir. Son dönemlerde yapılan bir PT çalışmasında (Altarelli et al. 2014), 46 kontrol, 35 disleksik olmak üzere 81 çocuğun MR görüntüleri karşılaştırılmıştır. Sonuçlar sadece disleksi gösteren erkek çocuklarda, normal erkek çocuklara göre PT'nin yüzey alanı bakımından daha fazla sağ taraflı asimetrinin olduğunu göstermiştir.

Dil işlemede diğer önemli bir yapı olan arcuate fasciculus'un zeka üzerinde ve akıl yürütme görevlerinde rol oynadığı tekrarlı bir şekilde gösterilmiştir (Lebel \& Beaulieu 2009). Lebel ve Beaulieu (2009), insan beyninde dilin hem işlev hem de yapı bakımından yanallaşmasının bir örneği olan arcuate fasciculus'un çocuklardaki ve adölasanlardaki asimetri örüntüsünü incelemek için sağlıklı sağ el kullanan 5-30 yaş arasındaki örneklemde difüzyon tensor görüntüleme (DTI) ve traktografi kullanmış ve katılımcılar üzerinde bilişsel incelemeler yapmıştır. Büyük bir bölümü 5-13 yaş arası alt gruptan oluşan katılımcıların çoğunda fraksiyonel anisotrofi ve arcuate fasciculus'un yollarının sayısı sol hemisferde, sağ hemisferden anlamlı şekilde daha yüksek bulunmuştur. Çalışma, çocuklarda, adölasanlarda ve genç yetişkinlerde sol taraflı yanallaşmanın olduğunu göstermiş ve çocuklardaki spesifik bilişsel becerilerle yapısal beyaz madde 
yanallaşması arasında bir ilişkinin olduğunu göstermiştir. Genel olarak, sol-yanallaşmış çocuklar fonolojik işlemede, sağ-yanallaşmış gruba göre daha iyi performans göstermiştir.

Normal dil gelişimi yaşamın ilk yıllarında çok hızlı gelişen bir süreç olmakla birlikte, dil ile ilgili uzmanlaşma çocuklukta ve ergenlikte artarak devam etmektedir. Dil anlama ve dil üretme normal dil gelişiminin iki bileşeni olarak ele alınmaktadır. Dil işlemede gözlenen sola ilişkin yanallaşmadaki artışın ve daha odaklanmış dil üretme ağının bu sürecin sinirsel korelasyonları olduğu düşünülmektedir. Lidzba, Schwilling, Grodd, Krageloh-Mann ve Wilke (2011), çocuklarda, adölasanlarda ve genç yetişkinlerde (6-24 yaş) bir dil anlama (Bip Hikayeleri / Beep Stories) ve bir dil üretme (Sesli harf tanımlama) görevi sırasında fMRI kullanarak sağ ve sol hemisferin bu iki göreve katkısını incelemişlerdir. Dil anlama görevi için yaşla birlikte daha odaklanmış çift taraflı superior temporal girus aktivitesi bulunurken, yanallaşma örüntüsü yaşla birlikte artmamıştır. Bu nedenle, dil anlamanın sinirsel temellerinin geç çocuklukta çift taraflı ağ üzerine kurulduğu düşünülmektedir. Dil üretme ile ilgili ağda ise, yaş ile birlikte artan odaklanma ve yanallaşma örüntüsü bulunmuştur. Sadece dil anlama görevindeki yanallaşma, sözel IQ ile ilişkili bulunmuştur. Buna göre daha yüksek sözel IQ, daha fazla sağ hemisferin aktivasyonu ile iliş̧kili bulunmuştur. Normal koşullarda sol hemisfer, dil ile ilişkili işlevlerde daha fazla rol oynamakla birlikte, sunulan bulgular dil anlamada her iki hemisferin birlikte kullanımının bir avantaj sağladığına işaret etmektedir.

Daha küçük çocuklarla yapılan bir nörogörüntüleme çalışmasında (Kikuchi et al. 2011) nonivazif bir beyin görüntüleme tekniği olan magnetoansaflografi (MEG) sistemi ile okul öncesi (32-64 aylık; \% 96's1 3-4 yaşında) sağ elini kullanan çocuklarda hareketli imgelerle anlatılan hikayeleri dinleme sırasındaki beyin ağları incelenmiştir. Sonuçlar, teta band aktivitesindeki (6-8 Hz) parietotemporal uyumlulukta sol baskınlı̆̆ının olduğunu ve bunun özellikle dil ile ilgili becerilerdeki yüksek performans ile ilişkili olduğunu göstermiştir. Benzer bir EEG çalışmasında Hug-Michel, Stegmaier, Zwicker ve Braker (1998) çocuklarda işitsel sözel (kısa anlamsız cümleler) ve sözel olmayan uyarıcılara (sesler / tonlar) verilen EEG tepkiselliğindeki değişiklikleri incelemişlerdir. Sadece sözel uyarıcılara verilen tepkilerde hemisferler arasında farkl1lık gösterilmiştir: Frontotemporal / temporalde sol hemisfer; parasantralde bir sağ hemisfer baskınlığı gözlenmiştir.

Öte yandan, sağ ve sol el kullanan kişilerde dildeki yanallaşmanın farklı olabileceği düşünülmektedir. Bu nedenle, Szaflarski ve arkadaşları sağ ve sol elini kullanan 5-18 yaş arası çocuklarda kelime türetme görevi sırasında fMRG kullanarak dil gelişimini incelemiştir. Frontal alanlar incelendiğinde sol el grubunda \%85 sol-hemisferik dil yanallaşması, \%11 simetrik aktivasyon ve \%4 sağ hemisferik yanallaşma gösterilmiştir. Sağ elini kullanan çocuklarda ise $\% 93$ sol hemisferik yanallaşma, \%6 simetrik aktivasyon örüntüsü ve \%2 sağ hemisferik yanallaşma gösterilmiştir. Temporo-parietal bölgeler temel alındığında sol elini kullanan çocukların \%67'si sol-baskın, \%22'si simetrik ve \%11'i sağ-baskın bulunmuş; sağ elini kullanan çocuklarda bu değerler \%91, \%7 ve \%2 olarak bulunmuştur. Sol hemisferik dil yanallaşmasının her iki grupta yaş ile birlikte arttığı; ancak kızlarla erkekler karşılaştırıldığında farklı yanallaşma yolları olduğu görülmüştür. Sol elini kullanan çocuklardaki atipik dil yanallaşma insidansı da yetişkinlerde rapor edilene benzer bulunmuştur. Bu bulgular, sağ ve sol el kullanan çocuklardaki dil yanallaşmasında yetişkinlerinkine benzer mekanizmaların kullanıldığını ve genel olarak sol hemisferik yanallaşmanın olduğunu göstermiştir.

\section{Sözel Bilgi İşlemeye İlişkin Yapılan Davranışsal Çalışmalar}

Sözel görevlerdeki hemisferik asimetriler dikotik dinleme yöntemi ile davranışsal boyutta da çalışılmaktadır. Bir standart dikotik dinleme testi sırasında kulaklıklar yardımıyla katılımcının her bir kulağına farklı olmak üzere iki ses ya da konuşma aynı anda sunulur. Sonra, katılımcı- 
lara ne duyduğu sorulur. Katılımcının cevabına göre hangi kulağın (zıt yöndeki hemisferin) ilgili görevde baskın olduğu anlaşılır. Çocuklarda dikotik dinleme yöntemi kullanılarak yapılan bir grup çalışma da genel olarak sağ kulak / sol hemisfer avantajı olduğuna işaret etmektedir: Örneğin, Duvelleroy Hommet ve arkadaşları (1997) test sırasında sağ kulak (sol hemisfer) avantajı bulmuşlar; ancak tekrar test sırasında sağ kulak avantajının ortadan kalktığını gözlemişlerdir. Dikotik dinleme paradigmasının kullanıldığı diğer bir çalışmada Asenova (2007) ilkokul çocuklarında hem duygusal hem de nötr kelimeler için bir sol hemisfer avantajı olduğunu bulmuştur.

Christianson, Saisa, Hugdahl ve Asbjornsen (1992), hemisferik asimetrileri gelişimsel bir perspektiften değerlendirmek için dikotik dinleme ve görsel yarı-alan testini kullanmıştır. İlk deneyde 8-11 yaş arasındaki çocuklara dikotik dinleme tekniği kullanılarak dağınık kelimelerden oluşan listeler sunulmuş̧ur. İkinci deneyde ise görsel yarı-alan tekniği kullanılarak bilindik nesnelerin resimleri sunulmuştur. İki deneyde de tanımlama, serbest çağrışım ve kelimeleri/ resimleri hatırlamaya ilişkin ölçümler, tüm yaş grupları için sağ kulak avantajı ve sağ görsel yar1-alan avantaj1 (sol hemisfer) olduğuna işaret etmiştir.

Öte yandan, çocuklarda hangi hemisferin baskın olarak kullanıldığı okuma düzeyine göre de değişmektedir. Porta, Kraft ve Harper (2010), okuma düzeyi, kelime özellikleri ve bilişsel becerileri yönünden değişen 6-9 yaş arasındaki birinci, ikinci ve üçüncü düzey okuyucularda sağ ve sol temporal lob aktivasyonunun nasıl değiştiğini elektroensafologram ölçümleriyle incelemişlerdir. Bulgular alt düzey okuyucuların içeriğinden bağımsız olarak tüm sözel malzemeyi sol hemisfer ile değerlendirdiğini; üst düzey okuyucuların ise sözel malzemeyi semantik özelliğine bağl1 olarak sol ya da sağ hemisfer ile değerlendirebileceğine işaret etmektedir.

\section{Sağlıklı ve Hasta Grupların Karşılaştırılması}

Dil ile ilgili asimetrilerin anlaşılmasına katkıda bulunan bir diğer grup araştırma dil ile ilgili bozukluk gösteren çocuklar ve kontrolleri karşılaştırılmak üzere tasarlanmıştır. Örneğin, dil ve konuşma bozuklukları, otizm spektrum bozukluklarının (OSB) temel özelliklerindendir (Knaus et al. 2010). Dilde azalmış ya da tersine dönmüş asimetri OSB içeren pek çok bozuklukta görülmektedir. Knaus ve arkadaşları (2010), dilde tipik sol hemisfer yanallaşması gösteren bireylerle atipik (çift taraflı ya da sağ) asimetri gösteren bireylerin Presilvian dil bölgelerindeki gri madde hacmini ve dil becerilerini karşılaştırmışlardır. OSB gösteren adölasan erkek çocuklar ve tipik gelişim gösteren adölasan erkek çocuklar karşılaştıılmıştır. Tipik sol presilvian yanallaşması gösteren katılımcılar, hem OSB'de hem de kontrollerde atipik gruba göre, daha küçük frontal dil bölgesi hacmi göstermiştir. Tipik dil asimetrisi gösteren grubun çoğu kontrol grubundaki sağ el kullanan ve çok azı da OSB gösteren sol el kullanan çocuklardan oluşmuştur. Atipik dil yanallaşması, OSB'de kontrol grubundan daha yaygın olarak bulunmuştur. Bu bulgular, dilin yanallaşması ve dil bölgesi anatomisi arasındaki bağlantıya destek sağlamaktadır.

Gage ve arkadaşları (2009) da işitsel dil korteksindeki hemisferik asimetrileri incelemek üzere otistik bozukluğu olan çocuklarda MRI kullanarak planum temporale (PT) üzerinde morfometrik bir çalışma yapmışlardır. Sağlıklı bireylerde sol hemisferde daha büyük olan PT, otistik erkek çocuklarında sağ taraflı asimetri göstermiştir. Veriler birlikte ele alındığında, otizm bozukluğu olan çocuklarda PT'nin daha düşük işlev görmesi için farklı bir gelişimsel yolağın olabileceğine, hem prenatal hem postnatal yaşantıların PT asimetrisinde rol oynayabileceğine ilişkin kanıtlar sağlamıştır.

\section{Sayısal Beceriler}

Çocuklarda ve bebeklerde yapılan davranışsal çalışmalar sayı algısının, tanımının ve temel hesaplama becerilerinin sözel olmayan organizmalarda bile var olduğunu ortaya koymuştur. 
Jordan, Kaplan, Olah, ve Locuniak (2006) anaokulu çocuklarında "sayı duyumu"na ilişkin olarak cinsiyet farklı1ığı olduğunu rapor etmiştir. Erkeklerin bu konuda daha üstün bir duyuma sahip olduğunu öne sürmüştür. Buna karşın Bull, Wendy ve Nordmann (2009) 5 yaşındaki çocukların aritmetik becerilerinde bir cinsiyet farkı gözlememiştir. Ayrıca, çocuklarda erken sayma ve genel matematik becerileri ile görsel-uzamsal becerilerin ilişkili olduğunu gösteren çalışmalar da mevcuttur (Bull, Wendy \& Nordmann 2009).

\section{Beyinde Sayısal İşlemlere İlişsin Yapısal ve İşlevsel Asimetriler}

Lezyon ve beyin görüntüleme çalışmaları, insanlarda sol ve sağ intraparietal alanlarda yer alan özgün sinirsel yapıların sayılar ve sayısal ilişkilere ilişkin bilgiyle bağlantılı olduğunu göstermiştir (Dehaene, Dehaene-Lambertz \& Cohen 1998). Örneğin, görüntüleme çalışmaları farklı karmaşıklıktaki farklı işlemlerin kullanıldığı mental aritmetik görevleri sırasında inferior parietal ve lateral frontal bölgelerde aktivasyonlar olduğunu göstermektedir (Fehr, Code \& Herrmann 2007). Fehr, Code ve Herrmann (2007) kendi fonksiyonel görüntüleme çalışması ise tüm aritmetik işlemlerde (toplama, çıkarma, çarpma, bölme) ortak olarak sağ prekuneus, sol ve sağ orta ve superior frontal alanlarda aktivasyon olduğunu göstermiştir.

Dehaene, Dehaene-Lambertz ve Cohen (1998) ise rakamlara ilişkin işlemlerde uyarcının içeriğine bağlı olarak aktive olan beyin hemisferinin değişebileceğini rapor etmiştir. Klein, Moeller, Nuerk ve Willmes (2010), sözel olarak verilen aritmetik bilgisinin işlenmesinde çift taraflı bir aktivasyon bulmuş; ancak, büyüklükle ilgisi olmayan eşitlik ifadeleri söz konusu olduğunda sol hemisferin intraparietal sulkusunda aktivite gözlemişlerdir. Bununla birlikte, toplama gibi karmaşı problemler çift taraflı medial frontal girusta daha fazla aktivasyona yol açarken, çıkarma işlemi, sağ presentral girusta ve talamusta ayrıca sol hemisferdeki inferior parietal lobda aktivasyona yol açmıştır.

Öte yandan, Kadosh, Bien ve Sack (2012) sağ ve sol parietal kortekse transmagnetik uyarım (TMS) yaparak otomatik ve istemli sayı işleme performansını inceledikleri çalışmalarında sağ parietal korteksin uyarılmasının sayı işleme sürecinde bozulmaya yol açtı̆̆ını; ancak, sol parietal korteksteki uyarımın böyle bir bozulma ile sonuçlanmadığını bildirmiştir.

Beyin hasarı çalışmaları da aritmetik işlemelerdeki hemisferik özelleşmelere ilişkin olarak bilgi verici olmaktadır. Rosca (2009) sol parietal lob lezyonu ve sol bazal ganglia lezyonuna sahip iki hastada basit aritmetik işlemlerde, aritmetik kurallarını kullanmada ve zihinsel veya yazılı karmaşı hesaplamalarda bozulmalar olduğunu gözlemiştir. Rosca'nın (2009) bulguları sol hemisferin aritmetik işlemlerdeki rolüne ilişkin görüşü desteklemiştir. Bu görüşü destekleyen başka bir çalışmada (Funnell, Colvin \& Gazzaniga 2007), bir ayrık-beyin hastasında iki hemisferin basit hesaplamalardaki rolü incelenmiștir. Deneyler, basit hesaplamalarda sol hemisferin, sağ hemisferden daha üstün olduğunu göstermiştir. Sağ hemisfer yaklaşık çözüme ulaşma kapasitesine sahip olmakla birlikte, tam sonucu elde etmede başarısız olmuştur.

Sağ elini kullanan yetişkinlerin çoğunda dil ve aritmetikte sol hemisfer özelleşmesi gözlendiği bulgusundan yola çıkan Pinel ve Dehaene (2010) bu ortak yanallaşmanın tüm dil ve sembolik işlemlerdeki bir sol hemisfer yanallaşması olup olmadığını incelemek için "cümle dinleme" ve "zihinsel hesaplama" sırasında ortak olarak aktive olan bölgeleri incelemişlerdir. Pinel ve Dehaene (2010) bazı ortak yanallaşma örüntülerinde birlikte değişimin olduğunu gözlemişlerdir ve bu sinirsel görüntüleme sonuçlarına dayanarak, çocuklukta sembolik aritmetiğe ilişkin geç yanallaşma sürecinin, linguistik sembollerin gelişimini izlediğini öne sürmüşlerdir.

Çocukların aritmetik hesaplamalarında gösterdikleri hemisferik asimetrilere ilişkin az sayıda çalışma mevcuttur. Mondt ve arkadaşları (2011) çift ve tek anadile sahip olan çocuklarla yaptıkları çalışmada aritmetik işlemler sırasında her iki grupta da sol hemisferde görsel-motor oksipito-frontal ağın aktive olduğunu gözlemişlerdir. 
Hunter ve arkadaşları (2005) ise derin olmayan beyin hasarına uğrayan çocuklarla ve hasarı olmayan çocuklarla proton MR spektroskopisi kullanarak yaptıkları çalışmada, sol frontoparietal bölgede nörometabolit değerlerinin, sağ frontoparietal bölgeden daha büyük olduğunu ve sol frontal kolin seviyesinin aritmetik beceri ile ilgili olduğunu bulmuşlardır. Çocukların aritmetik becerilerindeki yanallaşmasına ilişkin az sayıdaki çalışma, dil becerisinde olduğu gibi sol hemisferin bu konuda daha baskın bir rol oynayabileceğine işaret etmektedir.

\section{Yüz İşleme}

Literatürün kritik bir incelemesi yapıldığında yüzlerin yaşamın ilk 6 ayından sonra ayrı bir obje sınıfı olarak görülmeye başlandığı görüşü desteklenmektedir. Bu dönemde yüz tanımanın altında yatan nöral sistemler aktive olmaya başlamaktadır (Nelson 2001). Muhtemelen yüzlere maruz kalma ile ilgili nöral sistemlerin etkileşimi yüz algısına ilişkin hemisferik özelleşmelerin gelişiminde rol oynamaktadır. Yüz işlemeye ilişkin hemisferik asimetriler, sözel işlemlerde olduğu gibi beyin görüntüleme teknikleri, görsel yarı-alan tekniği ve ayrıca birleştirilmiş yüz uyarıcıları kullanılarak çalışılmaktadır.

\section{Yüz İşlemeye İlişskin Yapılan Davranışsal Çalışmalar}

Yüz işlemeye yönelik hemisferik özelleşmelerin test edildiği önemli işlem yollarından birisi birleştirilmiş (chimeric) yüz uyarıcılarının sunumudur. Birleştirilmiş yüz uyarıcısı, bir yüz fotoğrafının bir yarısı ile başka bir yüz fotoğrafının diğer yarısının birleştirilmesinden oluşturulur. Yüze karşıdan bakıldığında, görüntünün sağ tarafının doğrudan beynin sol hemisferine ve sol tarafının ise doğrudan beynin sağ hemisferine gittiği varsayıldığı için söz konusu uyarıcılar yüz işlemede sağ ve sol hemisfer farkını çalışmak için kullanılır. Örneğin, sol yarısı duygusal ifade taşıyan yüzden, sağ yarısı nötr ifade taşıyan yüzden oluşturulan bir yüzün birleştirilmiş yüz uyarıcısı olarak kullanıldığını düşünelim. Benzer şekilde sağ yarısı duygusal ifade taşıyan, sol yarısı nötr ifade taşıyan yüzden oluşturulan ikinci bir yüz uyarıcısının olduğunu düşünelim. Söz konusu iki uyarıcı, deneklere gösterildiğinde deneklerin hangi yüzü daha ifade edici bulduğundan ya da deneklerin değerlendirme süresinden hemisferik özelleşmelerine ilişkin çıkarımlarda bulunulur. Eğer denek kendisinin sol görsel yarı alanına düşen yüzü daha ifade edici olarak değerlendirmişse, deneğin bu görevde sol görsel alan yanlılığı dolayısıyla sağ hemisferik başatlığ gösterdiği çıkarımı yapılır. Yetişkinlerle yapılan çalışmalar (Wirsen, Klinteberg, Levander \& Schalling 1990; Rhodes 1993; Burt \& Perrett 1997; Indersmitten \& Gur 2003; Schweinberger, Baird, Blümler, Kaufmann \& Mohr 2003) yüz algısında sağ hemisfer baskınlığı olduğuna işaret etmektedir.

Aljuhanay ve arkadaşları (2010) da çocuklarda yüz işleme sürecinin ne zaman yetişkinlerdekine benzer hale geldiğini incelemek için 5 yaşındaki çocuklara birleştirilmiş yüz uyarıcıları sunmuşlardır. Sonuçlar, yetişkinlerde olduğu gibi bu yaş grubundaki çocuklarda da sağ hemisfer yanlılığının olduğunu göstermiştir. Bu yöntemle McCleery, Akshoomoff, Dobkins ve Carver (2009) 10 aylık sağlıklı çocuklarda bile yüz algısına ilişkin asimetrilerin varlığını göstermiştir. Söz konusu bulgular yüz algısına ilişkin olarak doğuştan gelen bir sağ hemisfer eğiliminin olduğunu göstermektedir.

Diğer bir çalışmada (Chiang, Ballantyne \& Traunet 2000), 6-16 yaş arasındaki normal gelişime sahip çocuklara serbest görüş koşulunda birleştirilmiş yüz uyarıcılarını sunarak, çocuklarda algisal asimetri ve hemisferik yanallaşma incelenmiştir. Çocuklara duygu (mutlu yüz), cinsiyet, çokluk ve şekle ilişkin yüz uyarıcıları sunmuşlardır. Bulgular, genel sol yarı alan etkisinin 6 yaşlarında belirdiğini ve bu sol yarı alan tercihinin 10 yaşlarında daha da belirgin hale geldiğini göstermiştir. Bu bulgular yüzleri işlemede yaş ile belirginlik kazanan sağ hemisfer baskınlığının sağlıklı gelişime işaret ettiğini göstermektedir. 


\section{Sağlıklı ve Hasta Grupların Karşılaştırılması}

McCleery, Akshoomoff, Dobkins ve Carver'ın (2009) otizme yatkınlık ile hemisferik asimetri arasındaki ilişkiyi incelediği bir ERP çalışmasında çocuklara yüz ve oyuncak resimleri gösterilmiş ve kortikal tepkiler ölçülmüştür. Çalışmada düşük riskli çocukların, yüksek riskli çocuklara göre daha fazla hemisferik asimetri gösterdiği bulunmuştur. Son dönemlerde otizm ile ilişkili olarak yapılan bir çalışmada (Keehn, Vogel-Farley, Tager-Flusberg \& Nelson 2015) yüksek ve düşük otizm riski taşıyan 6-12 aylık bebeklere tanıdık ve tanıdık olmayan yüz fotoğrafları gösterilmiş; EEG ile sağ ve sol beyin tepkileri incelenmiştir. Araştırma bulguları yüksek otizm riski taşıyan bebeklerin, düşük risk taşıyan bebeklerin aksine sol hemisfer aktivitesi gösterdiğine işaret etmiştir. Düşük riskli bebekler sağ hemisfer aktivitesi göstermiştir. On iki aylıkken daha fazla sol taraflı asimetri gösteren bebeklerin daha sonraki y1llarda otizm bozukluğunun kriterlerini karşıladıkları bulunmuştur. Dolayısıyla, yüzlere ilişkin atipik hemisferik özelleşmenin otizmin erken dönem bir işareti olabilceği düşünülmektedir.

Öte yandan doğuştan sağır olan 13-14 yaşındaki çocukların yüz işleme görevinde (Szelag, Wasilewski \& Fersten 1992) ve yüzdeki duyguyu değerlendirmede (Szelag \& Wasilewski 1992) sağır olmayan çocuklardan farklı olarak herhangi bir hemisferik asimetri göstermedikleri gözlenmiştir. Söz konusu bulgular işitsel bilginin işlenmediği bir beyinde, yüz işlemeye ilişkin olarak da bir özelleşmenin ortaya çıkmadığına işaret etmektedir. Bu tip bir beyin organizasyonunda sözel bilginin işlendiği sol beyin özelleşmesine ve yüz bilgisinin işlendiği bir sağ hemisfer özelleşmesine ihtiyaç duyulmamakta gibi görünmektedir. Her iki hemisfer de yüz ile ilgili bilgiyi eşit düzeyde işleyebilmektedir.

Birleştirilmiş yüz uyarıcıları kullanarak yapılan bir çalışmada (Bava, Ballantyne, May \& Trauner 2005) doğuştan tek yönlü beyin hasarı olan çocuklar ile tipik gelişime sahip eşleştirilmiş kontrol grubu, sol görsel alan yanlılığ 1 göstermesi bakımından karşılaştırılmıştır. Kontrol grubunda beklendiği gibi bir sol yarı-alan yanlılığı bulunurken; sol hemisfer hasarının varlığında yine sol-görsel yarı-alan yanlılığı artarak gözlenmiştir. Çünkü yüz algısından sorumlu sağ hemisfer hasar görmemiştir. Ancak, sağ hemisfer hasarı sonucunda daha az yanallaşmış işlemin olduğu görülmüştür. Lezyon büyüklügüne ilişkin incelemeler, sağ hemisferdeki büyük lezyonların tipik sol yanlılığın tersine dönmesi ile ilişkili olduğunu gösterirken, küçük lezyonlarda kontrollerdekine benzer şekilde sol görsel yarı-alan yanlılı̆̆ bulunmuştur. Bava, Ballantyne, May ve Trauner'a (2005) göre erken yaşlardaki her iki hemisferden birine gelen hasar sözel olmayan uyarıcıları işlemeye ilişkin hemisferik tercihi değiştirmektedir. Bu çalışma ile çocuklarda yüz algısında sağ hemisferin baskın olduğu; ancak bu hemisfere gelecek hasarın büyük olması sonucunda yüz işlemeye ilişkin sinirsel ağların değișebildiği gösterilmiştir. Öte yandan bir başka grup araştırmacının (de Schonen et al. 2005) sağ ya da sol temporal korteks hasarlı çocuklarla yaptığı bir çalışmada yüz işlemenin bu alanlarda oluşan hasardan sonra çok kolay gelişemediği; yüz işleme sisteminin gelişimi için hem sağ hem de sol hemisferin dahil olmasının gerekli olduğu öne sürülmüștür.

\section{Görsel-Uzamsal İşlemler}

Görsel-uzamsal beceri, iki boyutlu ya da üç boyutlu figürleri zihinsel olarak değişimleyebilme yeteneği olarak tanımlanmaktadır. Uzamsal beceriler ile motor performansın birbiriyle ilişkili olduğu öne sürülmektedir (bk. Hoyek et al. 2014). Yetişkinlerde görsel-uzamsal becerilerdeki yanallaşmaya iliş̧in yapılan çalışmalar (Smith \& Milner 1981; Kessels et al. 2001; Bayer \& Hausmann 2009) sağ hemisferin görsel-uzamsal becerilerde önemli bir role sahip olduğuna işaret etmektedir. Piaget ve Inhelder'a (1967, akt. Yılmaz 2009) göre çocukların görsel-uzamsal becerileri 12 yaşından önce yetişkinlerin düzeyine ulaşamamaktadır. Öte yandan, Huttenlocher ve Newcombe'a (2000, akt. Yılmaz 2009) göre bazı uzamsal beceriler 12 yaştan çok önce geliş- 
meye başlamaktadır.

\section{Beyinde Görsel-Uzamsal İşlemeye İlişkin Yapısal ve İşlevsel Asimetriler}

Jansen-Osmann ve Heil (2007) çocuklarda, ergenlerde ve yetişkinlerde harflerle yapılan bir zihinsel döndürme işlemi sırasında tepki süresi, doğruluk ve olay-bağımlı potansiyelleri karşılaştırmışlardır. Doğruluk oranı yaş ile birlikte artmıştır. Tüm gruplarda parietal elektrotlarda olay-bağımlı amplitüt değişimlerinin olduğu bulunmuştur. Bu etkinin çocuklarda sol tarafta yanallaştı̆̆ı; ancak, yetişkinlerde çift taraflı olduğu gözlenmiştir.

Tsujii, Yamamoto, Masuda ve Watanabe (2009) yaptıkları boylamsal çalışmada görsel uzamsal çalışma belleği görevi sırasında 5-7 yaş arasında çocukların frontal kortekslerinde oluşan aktiviteyi near-infrared spectroscopy (NIRS) kullanarak karşılaştırmıştır. Sekiz çocuk çalışmaya 5 yaşındayken ve 7 yaşındayken katılmıştır. Davranışsal analizler, büyük çocukların çalışma belleği görevini daha doğru ve hızlı olarak yaptığını göstermiştir. NIRS analizleri büyük çocuklarda sağ hemisfer baskınlığı olduğunu; buna karşın daha küçük çocuklarda hiçbir hemisferik asimetrinin olmadığını göstermiştir. Ayrıca, 5 yaşından 7 yaşına kadar daha güçlenmiş yanallaşma gösteren çocukların performansları da artmıştır.

Görsel-uzamsal becerilerde cinsiyet farklılı̆̆ olduğu da öne sürülmektedir. Yetişkinlerdeki zihinsel döndürme (mental rotation) performansı fonksiyonel serebral asimetrilerle birlikte giden bilişlerdeki en büyük cinsiyet farklılıklarından birisini ortaya çıkarmaktadır. Hahn, Jansen ve Heil (2010), 5 yaşındaki çocuklarda harflerin zihinsel döndürülmesini araştırmıştır. Zihinsel döndürme sırasındaki elektrofizyolojik beyin korelasyonları temelinde okul öncesi kız çocuklarının çift taraflı aktivite gösterdiğini; okul öncesi erkek çocuklarının beyin aktivitesinin ise, görevi çözmek için sadece zihinsel döndürmenin gerekli olduğu durumlarda açık bir şekilde sağ hemisfere yanallaştığını gözlemişlerdir. Zihinsel döndürme hızında ve doğruluğunda hiçbir cinsiyet farklılığı bulunmamıştır. Bu bulgular, zihinsel döndürmeye ilişkin hemisferik asimetrilerdeki cinsiyet farklılıklarının ergenlik dönemindeki hormonal değişikliklerle birlikte ortaya çıktığına işaret etmektedir.

Önceki çalışmalar çocukların zihinsel döndürme görevlerini 4 yaştan sonra cinsiyet farkı göstererek yaptıklarını ortaya koymuştur (Hoyek et al. 2012). Örneğin Ehrlich, Levine ve Goldin-Meadow (2006) 5 yaşındaki erkek çocukların eğitimden önce kız çocuklardan daha iyi uzamsal akıl yürütme performansı gösterdiğini bulmuştur. Son dönemlerde yapılan görüntüleme çalışmalarında ise bebeklikte bile cinsiyet farklılıklerı olabildiği ortaya konulmuştur (Hoyek et al. 2012). Hoyek ve arkadaşları (2012) ilkokul ve orta okul çocuklarında Vandenberg ve Kuse Zihinsel Döndürme Testinin (VMRT; Vandenberg \& Kuse 1978) ve benzer diğer 2-boyutlu uyarıcıların kullanılabilirliğini ve cinsiyet farkının olup olmadığını araştırmıştır. Sonuçlar sadece ortaokul grubunda erkeklerin kızlara göre daha yüksek performans gösterdiğini ortaya koymuştur. İlkokul çocukları hem VMRT'yi hem de 2-boyutlu zihinsel döndürme testini çözmekte zorlanmışlardır. Veriler, VMRT performansında 10 yaşında bir cinsiyet farklılığının ortaya çıktı̆̆ yolundaki bulguları desteklemektedir.

\section{Görsel-Uzamsal Becerilere İlişskin Yapılan Davranışsal Çalışmalar}

Çizgi ayırma testi dikkatin mekânsal dağılımını ölçmek üzere geliştirilmiş bir testtir. Bu testte kişiye çeşitli uzunlukta çizgiler verilerek çizgiyi orta noktasından dikey olarak bölmesi istenir. Görsel çizgi ayırma, tipik olarak beyin hasarı almış olan hastaların sağ hemisfer fonksiyonunu değerlendirmek için kullanılan güvenilir ve geçerli bir yanallaşma görevidir. Nörolojik olarak normal olan bireyler, çizgiyi objektif orta noktanın sol tarafından ayırma eğilimi gösterirken, sağ parietal hasar durumunda bireyler çizgiyi sağ tarafından ayırma eğilimi göstermektedir. Çünkü sağ hemisfer hasarı sol görsel alanın ihmal edilmesine yol açmaktadır. Dolayısıyla dikkat 
sağ tarafa daha fazla yönlendirilmektedir. Bu yanlılık "ihmal" (neglect) sendromu olan hastalarda açıkça ortaya konulmakla birlikte, sağl1klı gruplarda da bilişsel yükün arttığı durumlarda daha düşük düzeyde gözlenmektedir. Son bulgular çocukların ve daha yaşlı yetişkinlerin, bu görevde genç yetişkinlere göre daha güçlü uzamsal yanlılık gösterdiğine işaret etmektedir (Takio, Koivisto \& Hämäläinen 2014).

Çizgi ayırma testine paralel olarak, "bir insan çiz" testinde sağ elini kullanan Amerikalı çocukların sol alana ilişkin bir görsel yanlılık gösterdiği (çizimlerini orta noktanın sol tarafina yapmak gibi) Heller (1991) tarafından ortaya konulmuştur (Picard \& Zarhbouch 2014). Ancak benzer bir yanlılık sol elini kullanan çocuklarda gözlenmemiştir. Heller'in (1991) testine benzer şekilde Picard ve Zarhbouch (2014) sağ elini kullanan Fransız ve Morokkolu çocuklara "bir ağaç çiz" görevi vermişlerdir. Morokkolu çocuklar, Batılı çocuklardan farklı olarak sağdan sola doğru yazı yazma alışkanlığına sahip oldukları için sol alana ilişkin bir yanlılık göstermeyebilecekleri düşünülmüştür. Ancak bulgular içinde bulunulan kültürden bağımsız olarak hem Fransız hem de Morokkolu çocuklarda tek nesneyi merkezin sol tarafina doğru çizme eğiliminin olduğunu göstermiştir.

\section{Sağlıklı ve Hasta Grupların Karşılaştırılması}

Brisone ve Borgatti (1997) "Gelişimsel Să̆ Hemisfer Sendromu” olarak tanımlanan bozukluğa sahip olan çocuklarda güçlü sözel okuma ve söyleme becerilerine karşın, yetersiz paralinguistik beceri ve görsel-uzamsal işlevlerde nöropsikolojik bozulmalar olduğunu bildirmiştir.

Bir başka çalışmada Waldie ve Hausmann (2010) dikkat eksikliği ve hiperaktivite bozukluğu olan (ADHD) çocuklarları, gelişimsel disleksisi olan çocukları IQ ve cinsiyet bakımından eşleştirilmiştir. Amaç, bu iki bozuklukta gözlenen davranışsal eksikliklerin altında sağ hemisferdeki nörolojik anormalliğin yattığına ilişkin hipotezi test etmektir. Görsel çizgi ayırma performansı tepkide bulunan elin taradığı yön ve çizgi pozisyonunun işlevi olarak gruplar arasında karşılaştırılmıştır. Nörolojik olarak normal olan çocuklarda bulunan sola yönelik tipik eğilimin aksine, her iki klinik grup için de bir sağa yönelik yanlılık bulunmuştur; ancak bu eğilim çizgiyi ayırmak için hangi elin kullanıldığına bağlı olarak farklı derecelerde ortaya çıkmıştır. Bu bulgular, ADHD'si olan çocuklarda ve gelişimsel disleksisi olan çocuklarda korpus kallozumun (corpus callosum) veya/ve sağ fronto-parietal korteksin patolojisine işaret etmektedir.

Thomason ve arkadaşları (2009), çocuklarda (7-12 yaş) ve yetişkinlerde (20-29 yaş) çalışma belleği kapasitesini fMRI kullanarak karşılaştırmıştır. Araştırmacılar (2009) katılımcılara sözel ve uzamsal iki test yaptırmışlar ve aktive olan beyin bölgelerini incelemişlerdir. Çocuklar çalışma belleği yükü arttıkça yetişkinlerden daha fazla hata yapmışlardır. Ancak yetişkinler ve çocuklar benzer hemisferik asimetri örüntüsü (uzamsalda sağ hemisfer, sözelde sol hemisfer) göstermiştir. Bununla birlikte, çocuklar artan çalışma belleği yükü ile karşılaştıklarında yetişkinlerde olduğu gibi çoklu frontal ve parietal kortikal alanlarda artan aktivite gösterememiştir.

\section{Hemisferler-arası İletişim}

Pek çok bilişsel görevi yerine getirebilmek için o alanda özelleşmiş olan hemisferin aktivasyonu gerekli olmakla birlikte, özellikle daha karmaşık görevler için iki hemisfer arasındaki etkileşimin kritik olduğu görülmektedir. Hemisferler kendine özgü işlevleri yerine getirirken birbirinden tamamen bağımsız değildir. Korpus kallosum (corpus-callosum) adı verilen iki hemisferi birbirine bağlayan geniş sinir lifleri ve daha küçük diğer sinirsel bağlantılar sayesinde sağ ve sol hemisfer birbiriyle iletişim halindedir. Korpus kallosumun çıkarıldığı ayrık beyin (split brain) hastaları ile yapılan deneyler hemisferler arasındaki iletişimin pek çok bilişsel ve motor işlevin sürdürülmesi açısından gerekli olduğunu göstermiştir. 
Hemisferler arasındaki iletişimin yaş ile birlikte geliştiği düşünülmektedir. Çocuklarda özellikle çift elin kullanıldığı aktivitelerdeki beceri düzeyi de korpus kallosumun gelişimi ile birlikte artış göstermektedir (Gooijers \& Swinnen 2014). Buna paralel olarak ilerleyen yaş ile birlikte hemisferler arasındaki iletişime ilişkin ihtiyacın da arttığı öne sürülmektedir (Cherbuin \& Brinkman 2005).

Liegeois, Bentejac, de Schonen (2000) 19-28 aylık bebeklerde hemisferler arası etkileşimin olup olmadığını şematik bir yüz uyarıcısı kullanarak test etmiştir. Buna göre, daha küçük yaştaki bebekler uyarıcı tek taraflı sunulduğunda görevi başarabilirken, sadece 24 aylık çocuklar, uyarıcı çift taraflı sunulduğunda başarılı olabilmiştir. Sonuçlar iki görsel alana eşzamanlı olarak dikkat edilmesinin gerekli olduğu görsel görevlerde görsel bilginin hemisferler arası koordinasyonunun 24 ay gibi geç bir dönemde ortaya çıkabildiğine işaret etmiştir.

Başka bir çalışmada Liegeois ve de Schonen (2002) erken çocuklukta temel adlandırma ile ilgili görevlerde hemisferler arası işbirliği ve görsel dikkatin nasıl geliştiğini incelemişlerdir. Altı yaşındaki iki çocuğa iki farklı resim eş zamanlı olarak her iki görsel alanda (çift taraflı koşul) ya da iki resim bir yarı-alanda (sağda ya da solda tek taraflı koşul) sunulmuştur. Resmin işlenmesi tek görsel alan koşulunda iki hemisferden birisi ile yapılmakla birlikte, adlandırma söz konusu olduğunda sol hemisferin kullanımı mutlaka gerekli olmaktadır. Çift taraflı koşulda çocuklar sağ görsel alandaki resimleri adlandırmakta, sol görsel alandakileri adlandırmaya göre daha doğru tepkiler vermişlerdir. Bu farklılık, 2, 3, 4 yaşlarındaki çocuklar için anlamlı iken, 5 ve 6 yaşındaki çocuklarda anlamlı bulunmamıştır. Bu sonuçlar, erken çocuklukta sağ ve sol hemisferlerin adlandırma yeterliliğinin eşit derecede iyi gelişmediğini göstermiştir. Küçük çocuklarda sol hemisferin daha etkin olduğu gözlenmektedir: 2, 3, 4 yaşındaki çocuklar sol ve sağ görsel alandaki resimleri gördüklerinde önce sağ görsel alan resimlerini adlandırmıştır. Bunun aksine, 5 ve 6 yaşlarında çocuklar sol görsel alandaki resimleri önce adlandırmıştır ve tüm adlandırma performansı tavan düzeyine ulaşmıştır. 5 ve 6 yaşlarındaki bu dikkat değişmesine ilişkin şu yorum getirilmiştir: Tek taraflı sunum koşulunda sağ ve sol görsel alanlar arasında adlandırma doğruluğu bakımından bir farklılık bulunmamıştır. Çünkü hemisferler arası yolaklar işlevsel durumdadır: sağ hemisfere sunulan görsel uyarıcılar, en etkili olarak bilgide bir azalma olmaksızın sol hemisferde işlenebilir. Bulgular, bu yaş grubunda $(5,6)$ hemisferlerarası işbirliğinin geliştiğini desteklemektedir.

Banich, Passarotti ve Janes (2000) ise, 6,5 ve 14 yaşlarındaki çocuklara daha az karmaşık olan fiziksel tanımlama görevi ve daha karmaşık isim tanımlama görevleri vererek, görevin karmaşıklığına bağlı olarak hemisferler arasındaki etkileşimin değişip değişmediğini incelemişlerdir. Daha küçük yaştaki çocuklar daha az karmaşık görevlerde hemisfer-içi avantaj gösterirken, daha karmaşı görevlerde hemisferler arası avantaj göstermişlerdir. Araştırma sonuçları, çocuklarda da, yetişkinlerde olduğuna benzer şekilde görevin zorluğu arttıkça hemisferler arası iletişimin $\operatorname{arttığı~yönünde~bulgular~sağlamıştır.~}$

Sunulan literatürün 1şı̆̆ında çocuklarda da yetişkinlere benzer şekilde sözel ve sayısal işlemlerde sol hemisfer özelleşmesi, yüz işleme ve görsel-uzamsal becerilerde sağ hemisfer özelleşmesi olduğu görülmüştür. Ancak hemisferik özelleşmelerin yetişkinlerdeki düzeyine ulaşabilmesi için farklı bilişsel beceriler için farklı kritik dönemlerin olduğu gözlenmiştir. Çocuklardaki yüz işleme ve dil işleme gibi bazı hemisferik asimetri örüntülerinin doğuştan belirlenmiş olduğu gösterilmekle birlikte, bu asimetrilerin yaşantılar yoluyla değişebildiği de ortaya konmuştur. Özellikle hemisferlerden birine hasar gelmesi sonucunda tipik hemisferik asimetri örüntüsünde tersine dönme ya da ilgili işlevi her iki hemisferin birlikte yerine getirmesi mümkün olabilmektedir. Buna karşın genel olarak, artan yaş ve deneyim ile birlikte hemisferik özelleşmelerin sabitleştiği; ayrıca hemisferler arası etkileşimin yaş ile birlikte artış gösterdiği gözlenmiştir. 


\section{KAYNAKÇA}

Aljuhanay A., Milne E., Burt D. M. \& Pascalis O. (2010). "Asymmetry in Face Processing During Childhood Measured with Chimeric Faces". Laterality 15/4 (2010) 439-450.

Altarelli I., Leroy F., Monzalvo K., Fluss J., Billard C., Dehaene-Lambertz G. ve ark. (2014). "Planum Temporale Asymmetry in Developmental Dyslexia: Revisiting an Old Question”. Human Brain Mapping 35/12 (2014) 5717-5735.

Asenova I. V. (2007). "Hemispheric Asymmetry and Dichotic Perception of Emotional and Neutral Words in Junior School Children”. Psikhologicheskii Zhurnal 284 (2007) 82-89.

Atkinson R. L., Atkinson R. C., Smith E. E., Bem D. J. \& Nolen-Hoeksema S. (2002). Psikolojiye Giriş (Hilgard's Introduction to Psychology $12^{\text {th }}$ Edition). Çev. Y. Alogan. Ankara 2002.

Balsamo L. M., Xu B., Grandin C. B., Petrella J. R., Braniecki S. H., Elliott T. K. ve Gaillard W. D. (2002). "A Functional Magnetic Resonance Imaging Study of Left Hemisphere Language Dominance in Children”. Archives of Neurology 59/7 (2002) 1168-1174.

Banich M. T., Passarotti A. M. \& Janes D. (2000). "Interhemispheric Interaction During Childhood: I. Neurologically Intact Children”. Developmental Neuropsychology 18/1 (2000) 33-51. Doi: 10.1207/S15326942DN1801_3

Bava S., Ballantyne A. O., May S. J. \& Trauner D. A. (2005). "Perceptual Asymmetry for Chimeric Stimuli in Children with Early Unilateral Brain Damage”. Brain and Cognition 59/1 (2005) 1-10.

Bayer U. \& Hausmann M. (2009). "Estrogen Therapy Affects Right Hemisphere Functioning in Postmenopausal Women”. Hormones and Behavior 55/1 (2009) 228-234.

Brisone G. \& Borgatti R. (1997). "Developmental Right Hemisphere Syndrome: Cases Report”. SaggiNeuropsicologia Infantile Psicopedagogia Riabilitazione 23/2 (1997) 99-115.

Bull, R., Davidson,W. A. , Nordmann, E. (2009). Prenatal testosterone, visual-spatial memory, and numerical skills in young children. Learning and Individual Differences 20/3 (2009) 246-250.

Burt D. M. \& Perrett D. I. (1997). "Perceptual Asymmetries in Judgements of Facial Attractiveness, Age, Gender, Speech and Expression”. Neuropsychologia 35 (1997) 685-693.

Cherbuin N. \& Brinkman, C. (2005). "Practice Makes Two Hemispheres Almost Perfect". Cognitive Brain Research 24/3 (2005) 413-422.

Chiang C. H., Ballantyne A. O. \& Trauner D. A. (2000). "Development of Perceptual Asymmetry for Free Viewing of Chimeric Stimuli”. Brain and Cognition 44/3 (2000) 415-424.

Christianson S. A., Saisa J., Hugdahl K. \& Asbjornsen A. (1992). "Hemispheric-Asymmetry Effects in Children Studied by Dichotic-Listening and Visual Half-Field Testing”. Scandinavian Journal of Psychology 33/3 (1992) 238-246.

Dehaene S., Dehaene-Lambertz G. \& Cohen L. (1998). “Abstract Representations of Numbers in the Animal and Human Brain”. Trends in Neurosciences 21/8 (1998) 355-361.

de Schonen S., Mancini J., Camps R., Maes E. \& Laurent A. (2005). "Early Brain Lesions and FaceProcessing Development”. Dev Psychobiol 46 (2005) 184-208.

Duvelleroy Hommet C., Billard C., Gillet P., Barthez M. A., Santini J. J. \& Autret A. (1997). "Dichotic Listening to Words and Digits: Influence of Attentional Bias in Children". A N A E-Approche Neuropsychologique Des Apprentissages Chezl Enfant 9/1 (1997)10-15.

Ehrlich S., Levine S. C. \& Goldin-Meadow S. (2006). “The Importance of Gesture in Children's Spatial Reasoning”. Developmental Psychology 42 (2006) 1259-1268.

Fehr T., Code C. \& Herrmann M. (2007). "Common Brain Regions Underlying Different Arithmetic Operations as Revealed by Conjunct fMRI-BOLD Activation”. Brain Research 1172 (2007) 93-102.

Funnell M. G., Colvin M. K. \& Gazzaniga M. S. (2007). "The Calculating Hemispheres: Studies of a Split-Brain Patient”. Neuropsychologia 45/10 (2007) 2378-2386.

Gage N. M., Juranek J., Filipek P. A., Osann K., Flodman P., Isenberg A. L. et al. (2009). "Rightward Hemispheric Asymmetries in Auditory Language Cortex in Children with Autistic Disorder: an MRI Investigation”. Journal of Neurodevelopmental Disorders 1/3 (2009)205-214.

Gooijers J. \& Swinnen S.P. (2014). "Interactions between Brain Structure and Behavior: The Corpus 
Callosum and Bimanual Coordination”. Neuroscience and Biobehavioral Reviews 43 (2014) 1-19.

Hahn N., Jansen P. \& Heil M. (2010). "Preschoolers' Mental Rotation of Letters: Sex Differences in Hemispheric Asymmetry”. Cognitive Neuroscience 1/4 (2010) 261-267.

Hellige, J. (2001). Hemispheric asymmetry: What's right and what's left. Cambridge, NY: Harvard University Press.

Heller, W. (1991). Hemispatial biases in children on the Draw-A-Person Test. Developmental Neuropsychology, 7/2 (1991), 151-160.

Hoyek N., Collet C., Fargier P. \& Guillot A. (2012). “The Use of the Vandenberg and Kuse Mental Rotation Test in Children”. Journal of Individual Differences 33/1 (2012) 62-67.

Hoyek N., Champely S., Collet C. Fargier P. \& Guillot A. (2014). "Is Mental Rotation Ability a Predictor of Success for Motor Performance?”. Journal of Cognition and Development 5/3 (2014) 495-505.

Hug-Michel C., Stegmaier D., Zwicker F. \& Braker E. (1998). "Mapping of EEG Reactivity to Verbal and Non-Verbal Information in 11-Year-Old Children”. Klinische Neurophysiologie 29/2 (1998) 104-111.

Hunter J. V., Thornton R. J., Wang Z. J., Levin H. S., Roberson G., Brooks W. M. et al. (2005). "Late Proton MR Spectroscopy in Children After Traumatic Brain Injury: Correlation with Cognitive Outcomes". American Journal of Neuroradiology 26 (2005) 482-488.

Indersmitten T. \& Gur R. C. (2003). "Emotion Processing in Chimeric Faces: Hemispheric Asymmetries in Expression and Recognition of Emotions”. The Journal of Neuroscience 23/9 (2003) 3820-3825.

Jansen-Osmann P. \& Heil M. (2007). "Developmental Aspects of Parietal Hemispheric Asymmetry During Mental Rotation”. Neuroreport 18/2 (2007) 175-178.

Jordan N. C., Kaplan D., Olah L. N. \& Locuniak M. N. (2006). "Number Sense Growth in Kindergarten: A Longitudinal Investigation of Children at Risk for Mathematics Difficulties”. Child Development 77 (2006) 153-175.

Kadosh R. C., Nina B. \& Sack A. T. (2012). “Automatic and Intentional Number Processing Both Rely on Intact Right Parietal Cortex: Acombined fMRI and Neuronavigated TMS Study”. Frontiers in Human Neuroscience 6 (2012) 1-9.

Keehn B., Vogel-Farley V., Tager-Flusberg H. \& Nelson Charles A. (2015). “Atypical hemispheric Specialization for Faces in Infants at Risk for Autism Spectrum Disorder”. Autism Research 8/2 (2015) 187-198.

Kessels R. P. C., Kappelle L. J., de Haan E. H. F. \& Postma, A. (2001). "Lateralization of SpatialMemory Processes: Evidence on Spatial Span, Maze Learning, and Memory for Object Locations”. Neuropsychologia 40 (2001) 1465-1473.

Kikuchi M., Shitamichi K., Yoshimura Y., Ueno S., Remijn G. B., Hirosawa T. et al. (2011). "Lateralized Theta Wave Connectivity and Language Performance in 2-to 5-Year-Old Children”. Journal of Neuroscience 31/42 (2011) 14984-14988.

Klein E., Moeller K., Nuerk H-C. \& Willmes K. (2010). “On the Neuro-Cognitive Foundations of Basic Auditory Number Processing: An fMRI Study”. Behavioral and Brain Functions 6/42 (2010) 1-13.

Knaus T. A., Silver A. M., Kennedy M., Lindgren K. A., Dominick K. C., Siegel J. et al. "Language Laterality in Autism Spectrum Disorder and Typical Controls: A Functional, Volumetric, and Diffusion Tensor MRI Study”. Brain and Language 112/2 (2010) 113-120.

Lebel C. \& Beaulieu C. (2009). "Lateralization of the Arcuate Fasciculus from Childhood to Adulthood and its Relation to Cognitive Abilities in Children”. Human Brain Mapping 30/11 (2009) 3563-3573.

Lidzba K., Schwilling E., Grodd W., Krageloh-Mann I. \& Wilke M. (2011). "Language Comprehension vs. Language Production: Age Effects on fMRI Activation”. Brain and Language, 119/1 (2011) 6-15.

Liegeois F., Bentejac L. \& de Schonen S. (2000). "When Does Inter-Hemispheric Integration of Visual Events Emerge in Infancy? A Developmental Study on 19- to 28-Month-Old Infants". Neuropsychologia 38 (2000) 1382-1389

Liegeois F. \& de Schonen S. (2002). "Picture Naming in Young Children: A Developmental Study on Interhemispheric Collaboration”. Brain and Cognition 49/1 (2002) 123-137.

McCleery J. P., Akshoomoff N., Dobkins K. R. \& Carver L. J. (2009). “Atypical Face Versus Object Processing and Hemispheric Asymmetries in 10-Month-Old Infants at Risk for Autism”. Biological 
Psychiatry 66/10 (2009) 950-957.

Mondt K. Struys E., Van den Noort M., Baleriaux D., Metens T., Paquier P. et al. (2011). "Neural Differences in Bilingual Children's Arithmetic Processing Depending on Language of Instruction". Mind, Brain and Education 5/2 (2011) 79-88.

Nelson C. A. (2001). "The Development and Neural Bases of Face Recognition". Infant and Child Development 10/1-2 (2001) 3-18.

Pinel P. \& Dehaene S. (2010). "Beyond Hemispheric Dominance: Brain Regions Underlying the Joint Lateralization of Language and Arithmetic to the Left Hemisphere". Journal of Cognitive Neuroscience, 22 (1) 2010, 48-66.

Porta M. E., Kraft R. \& Harper L. (2010). "Hemispheric Asymmetry Profiles During Beginning Reading: Effects of Reading Level and Word Type”. Developmental Neuropsychology 35/1 (2010) 96-114.

Preis S., Jancke L., Schmitz-Hillebrecht J. \& Steinmetz H. (1999). "Child Age and Plenum Temporale Asymmetry”. Brain and Cognition 40/3 (1999) 441-452.

Rhodes G. (1993). "Configural Coding, Expertise, and the Right Hemisphere Advantage for Face Recognition”. Brain and Cognition 22/1 (1993) 19-41.

Rosca E. C. (2009). “Arithmetic Procedural Knowledge: A Cortical Circuit”. Brain Research 1302 (2009) 148-156.

Schweinberger S. R., Baird L. M., Blümler M., Kaufmann J. M. \& Mohr B. (2003). "Interhemispheric Cooperation for Face Recognition But Not for Affective Facial Expressions”. Neuropsychologia 41 (2003) 407-414.

Smith M. L. \& Milner B. (1981). "The Role fo the Right Hippocampus in the Recall of Spatial Location”. Neuropsychologia 19 (1981) 781-93.

Szaflarski J. P., Rajagopal A., Altaye M., Byars A. W., Jacola L., Schmithorst V. J. et al. (2012). "LeftHandedness and Language Lateralization in Children”. Brain Research 1433 (2012) 85-97.

Szelag E. \& Wasilewski R. (1992). "The Effect of Congenital Deafness on Cerebral Asymmetry in the Perception of Emotional and Nonemotional Faces”. Acta Psychologica 79/1 (1992) 45-57. Doi: 10.1016/0001-6918(91)90072-8

Szelag E., Wasilewski R. \& Fersten E. (1992). "Hemispheric Differences in the Perception of Words and Faces in Deaf and Hearing Children”. Scandinavian Journal of Psychology 33 (1992) 1-11. Doi: 10.1111/j.1467-9450.1992.tb00807.x

Takio F., Koivisto M. \& Hämäläinen H. (2014). "The Influence of Executive Functions on Spatial Biases Varies During the Lifespan”. Developmental CognitiveNeuroscience 10 (2014) 170-180.

Thomason M. E., Race E., Burrows B., Whitfield-Gabrieli S., Glover G. H. \& Gabrieli J. D. E. (2009). "Development of Spatial and Verbal Working Memory Capacity in the Human Brain". Journal of Cognitive Neuroscience 21/2 (2009) 316-332.

Tsujii T., Yamamoto E., Masuda S. \& Watanabe S. (2009). "Longitudinal Study of Spatial Working Memory Development in Young Children”. Neuroreport 20/8 (2009) 759-763.

Waldie K. E. \& Hausmann M. (2010). "Right Fronto-Parietal Dysfunction in Children with ADHD and Developmental Dyslexia as Determined by Line Bisection Judgements”. Neuropsychologia 48/12 (2010) 3650-3656.

Wirsen A., Klinteberg B., Levander S. \& Schalling D. (1990). "Differences in Asymmetric Perception of Facial Expression in Free-Vision Chimeric Stimuli and Reaction Time”. Brain and Cognition 12/2 (1990) 229-239.

Yilmaz H. B. (2009). "On the Development and Measurement of Spatial Ability". International Electronic Journal of Elementary Education 1/2 (2009) 83-96. 